\title{
Utility of $N$-Peracetylation of Proteins for Their Structure Determination by Mass Spectrometry
}

\author{
Roland S. Annan* and Klaus Biemann \\ Department of Chemistry, Massachusetts Institute of Technology, Cambridge, Massachusetts, USA
}

\begin{abstract}
Acetylation of the animo groups ( $N$-terminus and lysine) of proteins before enzymatic or chemical cleavage was explored as an approach to provide additional information in the course of the determination of amino acid sequences. The major advantage is the ability to differentiate glutamine from lysine, because only the latter is acetylated and thus increases in mass by $42 \mathrm{Da}$. Horse heart cytochrome $c$ could be fully $N$-actetylated and even on prolonged digestion with chymotrypsin underwent very little tryptic cleavage, in contrast to the native protein where this side reaction is extensive. Sperm whale myoglobin is more difficult to acetylate, but even at $40 \%-50 \%$ average acetylation, all 19 lysines could be identified unambiguously. $\Lambda$ proteolytic digest of acetylated protein is thus a useful component of strategies for the determination of the primary structure of proteins by tandem mass spectrometry. (J Am Soc Mass Spectrom 1993, 4, 87-96)
\end{abstract}

$\mathrm{T}$ The potential of mass spectrometry for the determination of the primary structure of proteins is now well established [1-3]. The strategy involves the digestion of the protein with proteolytic enzymes, partial separation of the digest by high-performance liquid chromatography (HPLC), determination of the molecular weights of the proteolytic peptides, and, finally, sequencing of the latter by using collisioninduced dissociation (CID) followed by tandem mass spectrometry (MS/MS). Fast-atom (or cesium ion) bombardment $(F A B)$ is the most widely used ionization method, although electrospray (ES) and matrixassisted laser desorption (MALD) have also been applied more recently. Because of its high specificity for cleavage at lysine and arginine, tryspin is generally the first protease chosen.

Only under exceptional circumstances would the data from a single digest contain sufficient information to deduce the complete sequence of a protein. It is therefore always necessary to analyze at least one digest obtained with a different enzyme, such as chymotrypsin, Endo Glu-C or Endo Asp-N. Trypsin (or Endo Lys-C) generates peptides with either arginine or lysine as the C-terminal amino acid (except for peptides representing the original $C$-terminus). This is useful in mass spectrometric peptide sequencing

*Present address: Department of Physical and Structural Chemistry, SmithKline Beecham Pharmaceuticals, King of Prussia, PA 19406.

Address reprint requests to Klaus Biemann, Department of Chemistry, Room 56-010, Massachusetts Institute of Technology, Cambridge, MA 02139. because it has been demonstrated that on CID, the presence of a basic amino acid will strongly influence fragmentation and favor fragment ions that encompass the site of the basic residue [4]. The CID spectra of tryptic peptides will therefore be dominated by $\mathrm{C}$ terminal fragment ions. For this reason, the resulting spectra are different from those generated by the other proteases, which produce peptides containing basic amino acids in the interior, at the $\mathrm{N}$-terminus, or none at all.

The amino acid lysine has two characteristics that are important for peptide sequencing by MS/MS. The basic $\varepsilon$-amino group is easily protonated and thus directs the fragmentation of the $(\mathrm{M}+\mathrm{H})^{+}$ion of the peptide, and, more important, lysine has the same nominal residue mass ( $128 \mathrm{u}$ ) as glutamine from which it differs by only $0.036 \mathrm{u}$. A difference in $128 \mathrm{u}$ between two fragment ions of the same ion type therefore indicates the presence of either Lys or Gln, which must then be differentiated by other means. One method is provided by the specificity of trypsin, which cleaves on the C-terminal side of Lys but not Gln. This information is reliablc in positive cases (i.e., where the tryptic cleavage occurs) but not in the negative instances, because there are situations where the enzyme does not cleave, such as the Lys-Pro bond or where Lys becomes a $\mathrm{C}$ - or $\mathrm{N}$-terminal amino acid (i.e., if it is preceded or followed by arginine in the original protein).

For all these reasons, it is necessary to be able to differentiate Lys from Gln independently, and this is 
generally achieved by acetylation of the peptide (or the HPLC fraction in which it occurs) [3, 5]. In addition to the $N$-terminal amino group, each lysine present adds $42 \mathrm{u}$ to the molecular weight of the peptide, and the residue mass of lysine is shifted to $170 \mathrm{u}$, whereas that of glutamine remains unchanged.

Because the acetylation needs to be performed on a number of peptides, we have explored a variation of the strategy outlined earlier, namely, acetylation of all lysines in the intact protein, followed by digestion with an enzyme that does not depend on the basic character of the lysine side chain. The resulting digest would consist of peptides where the mass coincidence of Lys and GIn is already eliminated, and the CID fragmentation directing effect of the basic amino acids is reduced to those peptides containing arginine and to a lesser extent histidine. Furthermore, all of the peptides generated by digestion of a protein in which all of the lysines are acetylated would have only one primary or secondary amino group left, namely, the $N$-terminus (except for the original $N$-terminal peptide). This would make it easier to derivatize this group with a substituent that contains a quarternary ammonium [6] or phosphonium group [7] for the purpose of generating $\mathrm{d}_{n}$ or $\mathrm{w}_{n}$ ions that are necessary to differentiate leucine from isoleucine $[4,8]$ and hydroxyproline [9]. Finally, cleavages at lysine, which occur frequently in lengthy chymotryptic digests because of unwanted tryptic activity, are eliminated by acetylation of the lysines.

The goal of this work was to evaluate the utility of $N$-peracetylation of proteins as an aid in the determination of their linear structure by mass spectrometry. After mass spectral analysis of a tryptic digest of the protein, a second digest with a different enzyme would be performed on the acetylated protein. We believe that acetylation will aid significantly in the analysis of the CID data from the second digest and facilitate the location of sequence overlaps. With the recent development of MALD [10] and ES [11], it has become very easy to accurately measure the molecular weights of proteins. We have used the former method to follow the acetylation reaction and evaluate the utility of such measurements for determining the number of acetyl groups incorporated.

\section{Experimental}

\section{Proteins, Enzymes, and Reagents}

Cytochrome $c$ from horse heart (lot C-7752), myoglobin from horse skeletal muscle (lot 75F7035), myoglobin from sperm whale skeletal muscle (lot 9350497), ubiquitin from bovine red blood cells (lot U-6253), glucagon (lot G-4250), glacial acetic acid, and acetic anhydride were purchased from Sigma Chemical Co. (St. Louis, MO). Trypsin (sequenal grade) and chymotrypsin were purchased from BoehringerMannheim (Indianapolis, IN).

\section{Sample Preparation}

$N$-Peracetylation of Proteins. Cytochrome $c$ was acetylated by dissolving $20 \mathrm{nmol}$ of the protein in $50 \mu \mathrm{L}$ of glacial acetic acid and adding an equal volume of acetic anhydride. The solution was heated for $3 \mathrm{~h}$ at $38{ }^{\circ} \mathrm{C}$. The reaction was stopped by adding $200 \mu \mathrm{L}$ of water and the reagents removed using a Speed Vac (Savant, Farmingdale, NY). The sample was not allowed to go to dryness. Additional water was added and the sample reevaporated until the $\mathrm{pH}$ was neutral, indicating that all of the reagents had been removed. The reagents can also be removed by HPLC with a $C_{18}$ (300- $\AA$ pore size) guard column, using $60 \%$ aqueous acetonitrile ( $0.5 \%$ trifluoroacetic acid) as the elution solvent. The sample volume was then reduced in a Speed Vac.

Under these conditions, serine, tyrosine, and, to some extent, threonine will also be acetylated. Treatment of the actylated protein with base for $2 \mathrm{~h}$ at room temperature will remove most of this unwanted $O$-acetylation. If the protein is to be digested with $0.1 \mathrm{M} \mathrm{NH}_{4} \mathrm{HCO}_{3}, 0.1 \mathrm{mM} \mathrm{CaCl}_{2}$ buffer at $\mathrm{pH}$ 8.5, any $\mathrm{O}$-acetylated tyrosine or serine will be hydrolyzed at this time.

Myoglobin was first converted to apomyoglobin by removal of the heme in a manner similar to the removal of the heme from hemoglobin [12]. Dry myoglobin (10-50 $\mathrm{nmol})$ was dissolved in $50 \mu \mathbf{L}$ of distilled deionized water. The apomyoglobin was precipitated by addition of a 100-fold excess volume of ice cold acetone $/ 0.3 \% \mathrm{HCl}$, left to settle for $15 \mathrm{~min}$ on ice and then pelleted with a laboratory centrifuge $(3000 \mathrm{~g})$. The supernatant was removed and the pellet washed once with ice cold acetone $/ 0.3 \% \mathrm{HCl}$, which was then removed after centrifugation. The residual acetone was removed under a stream of argon. The apomyoglobin was then dissolved in $25-50 \mu \mathrm{L}$ of $\mathrm{H}_{2} \mathrm{O}$, and $100 \mu \mathrm{L}$ each of glacial acetic acid and acetic anhydride were added. The acetylation and workup were carried out as described previously.

Tryptic and Chymotryptic Digestion. A solution of 10$50 \mathrm{nmol}$ of either the native or the acetylated proteins that had been concentrated into approximately $50 \mu \mathrm{L}$ of water was diluted with $100 \mu \mathrm{L}$ of $8 \mathrm{M}$ urea and denatured for $20 \mathrm{~min}$ at $38{ }^{\circ} \mathrm{C}$. The solution was then diluted with $400 \mu \mathrm{L}$ of $0.1 \mathrm{M} \mathrm{NH} \mathrm{NCO}_{3}, 0.1 \mathrm{mM}$ $\mathrm{CaCl}_{2}, \mathrm{pH} 8.5$, and the protein digested with either trypsin or chymotrypsin ( $2 \%$ by weight) at $37^{\circ} \mathrm{C}$. Both myoglobin digests (trypsin and chymotrypsin) were stopped after $6 \mathrm{~h}$ by adding $200 \mu \mathrm{L}$ of $0.5 \%$ trifluoroacetic acid. The cytochrome $c$ digests were terminated in a similar manner after $36 \mathrm{~h}$. The resulting peptides were fractionated by reversed-phase HPLC. An aliquot of the crude digest corresponding to 2-5 nmol was injected onto a Vydac protein $\mathrm{C}_{18}$ column $(4.6 \times 25 \mathrm{~cm})$ and eluted by using a gradient of $90 \% \mathrm{~A}\left(\mathrm{H}_{2} \mathrm{O}\right.$, 
$0.05 \%$ trifluoroacetic acid) to $65 \% \mathrm{~B}$ (acetonitrile, $0.05 \%$ trifluoroacetic acid) over $50 \mathrm{~min}$.

To prepare the samples for fast-atom bombardment mass spectrometry (FABMS) analysis, glycerol (1-2 $\mu \mathrm{L})$ was added to each fraction and the HPLC solvent removed with a Speed Vac. An aliquot from each fraction was analyzed by FABMS to determine the $(\mathrm{M}+\mathrm{H})^{+}$ions of the proteolytic peptides. Another aliquot from the same sample was later used to record the CID spectrum of the $(\mathrm{M}+\mathrm{H})^{+}$ions of the corresponding peptides.

\section{Fast-Atom Bombardment Mass Spectrometry}

The FABMS of peptides, dissolved in glycerol, was carried out in MS-I of a JEOL HX110/HX110 (JEOL Ltd., Akishima, Japan) high-resolution tandem mass spectrometer $\left(\mathrm{E}_{1} \mathrm{~B}_{1} \mathrm{E}_{2} \mathrm{~B}_{2}\right.$ configuration) at an accelerating voltage of $10 \mathrm{kV}$ and a mass resolution of $1: 2600$ (10\% valley). The JEOL Cs ${ }^{+}$ion gun was operated at $26 \mathrm{kV}$. Single scans were acquired between $\mathrm{m} / \mathrm{z} 200$ and 2000 in $0.8 \mathrm{~min}$. The instrument was calibrated by using $(\mathrm{CsI})_{n} \mathrm{Cs}^{+}$cluster ions. Mass spectra were acquired with a JEOL DA5500 data system running on a DEC PDP11/73 computer. All FABMS data are reported as the monoisotopic mass, unless otherwise noted.

\section{Tandem Mass Spectrometry}

Tandem mass spectrometry was carried out by using all four sectors of the JEOL HX110/HX110. Collisioninduced dissociation of protonated peptide molecules, selected by MS-I, took place in the field-free region after $B_{1}$, thus operating both MS-I and MS-II as double-focusing instruments. The collision cell potential was held at $3.0 \mathrm{kV}$; therefore, the ion collision energies were $7.0 \mathrm{keV}$. Helium collision gas was introduced into the collision chamber at a pressure sufficient to reduce the precursor ion signal by $65 \%-70 \%$. The CID mass spectra were necorded with $100-\mathrm{Hz}$ filtering at a rate to scan from $m / z 100$ to 6000 in 2.5 $\min$ (e.g., a CID mass spectrum from $\mathrm{m} / \mathrm{z} 50$ to 1950 requires $1 \mathrm{~min}$ ). The MS-I was operated at a resolution adjusted so that only the ${ }^{12} \mathrm{C}$-species of the protonated peptide molecule to be analyzed was transmitted. The MS-II was operated at a resolution of $1: 1000$ and was calibrated with a mixture of $\mathrm{CsI}, \mathrm{NaI}, \mathrm{KI}, \mathrm{RbI}$, and $\mathrm{LiCl}$ [13].

\section{Matrix-Assisted UV Laser Desorption Time-of- Flight Mass Spectrometry}

Spectra were acquired by using a modified Vestec VT2000 LD-TOF (VESTEC Corp., Houston, TX) operating at 30-kV accelerating voltage and equipped with a Laser Science $\mathrm{N}_{2}$ laser (LSI, Inc., Cambridge, MA). This laser produces UV light at $337 \mathrm{~nm}$ with 8-ns-wide pulses and was operated at a repetition rate of $5 \mathrm{~Hz}$.
Samples were mixed with a matrix of sinapinic acid (3,5-dimethoxy-4-hydroxycinnamic acid) and ionized by irradiation with the $N_{2}$ laser. Each spectrum is the sum of 50 laser shots.

\section{Results and Discussion}

The complete and lysine-specific acetylation of horse heart cytochrome $c\left(\mathrm{M}_{\mathrm{r}}=12360.1\right)$ [14] and sperm whale myoglobin $\left(M_{r}=17199.9\right)$ [15] with a mixture of acetic acid/acid anhydride has proved to be difficult, corroborating earlier findings [16]. Cytochrome $c$ was chosen because it digests very slowly and therefore, when using commercially available chymotrypsin, leads to extensive cleavage at lysine. As a result, 13 of the 20 peptides identified from the digest (Table 1) are due to trypsinlike activity.

When cytochrome $c$ containing 19 lysines and having an $\mathrm{N}$-acetyl blocked $\mathrm{N}$-terminus was acetylated, the MALD spectrum of the derivatized product (Figure 1) revealed an $(\mathrm{M}+\mathrm{H})^{+}$ion of $m / z \quad 13,211.0$ measured at the apex of the peak. This average $M_{r}$ of $13,210( \pm 13 \%$ or $\pm 0.1 \%)$ corresponds to the addition of 20 acetyl groups [i.e., one more than predicted for the number of lysines alone $\left.\left(M_{r}=13,200\right)\right]$. The peak is slightly broader than that of the internal standard owing to the inhomogeneity of the acetylation product (the centroid of the top $25 \%$ of the peak falls at $m / z$ 13,222.6).

After a 37-h digestion with chymotrypsin, a much more enzyme-specific peptide mixture (compare Table 2 with Table 1) was obtained, the components of which covered the complete sequence (see Table 2 and Figure 2). This is in marked contrast to the results from the chymotryptic digest of the native protein, where only $64 \%$ of the sequence could be accounted for. Because many of the lysines in cytochrome $c$ are located near each other, the undesired cleavages at lysine produced many small peptides, a significant number of which escaped detection. Because the acetylation of the lysines renders them inert to trypsin, the chymotryptic digest of acetylated cytochrome $c$ contains almost exclusively chymotryptic peptides, even after a 37-h digestion.

$\Lambda$ detailed inspection of the $F \Lambda B$ spectra of the HPLC fractions from the chymotryptic digest of acetylated cytochrome $c$ (Figure 3) revealed that all of the $\mathrm{M}+\mathrm{H}^{+}$ion signals corresponded to the mass-tocharge ratio values calculated for complete lysine acetylation, except for two. These two peptides $(\mathrm{M}+$ $\mathrm{H})^{+}=m / z \quad 850.6$ and 1167.4 , respectively, were $42 \mathrm{u}$ heavier than the $(\mathrm{M}+\mathrm{H})^{+}$ions of the peptides $(27-33)$ and $(27-36)$, both of which contained the threonine at position 28 (see sequences with $\underline{T}$ in Table 2 and an asterisk in Figure 2). Thus, this amino acid must be the locus of "overacetylation." Incubation of the acetylated protein and proteolytic peptides in ammonium bicarbonate at $\mathrm{pH} 8.5$ should remove any $O$-acetylation on serine and tyrosine. Threonine, however, although reacting more slowly than either serine 
Table 1. Chymotryptic digest of cytochrome $c$

\begin{tabular}{|c|c|c|}
\hline Position & $(\mathrm{M}+\mathrm{H})^{+}$measured $(\mathrm{FAB})^{\mathrm{a}}$ & Sequence \\
\hline $8-10$ & 407.3 & (K)KIF \\
\hline $11-22$ & $1991.3^{b}$ & (F)VOKC ... TVEK \\
\hline $11-26$ & $2370.0^{b}$ & (F)VOKC... GGKH \\
\hline $26-37$ & 1220.9 & (K)HKTGPNLHGLF \\
\hline $27-36$ & 1083.8 & (H)KTGPNLHGL. \\
\hline $27-35$ & 936.7 & (H)KTGPNLHGLF \\
\hline $28-36$ & 955.5 & (K)TGPNLHGLF \\
\hline $28-35$ & 808.6 & (K)TGPNLHGL \\
\hline $40-46$ & 677.4 & (K)TGOAPGF \\
\hline $40-48$ & 941.5 & (K)TGOAPGFTY \\
\hline $55-59$ & 604.4 & (N)KGITW \\
\hline $56-59$ & 476.4 & (K)GITW \\
\hline $60-65$ & 750.5 & (W)KEETL \\
\hline $60-67$ & 1042.7 & (W)KEETLMEY \\
\hline $60-68$ & 1155.3 & (W)KEETLMEYL \\
\hline $80-82$ & 410.3 & (K)MIF \\
\hline $87-97$ & 1365.8 & (K)KKTE... LIAY \\
\hline $88-97$ & 1237.8 & (K)KTER . . LIAY \\
\hline $89-97$ & 1109.6 & (KITERE... LIAY \\
\hline $88-98$ & 1351.1 & (K)KTER ... IAYL \\
\hline
\end{tabular}

${ }^{a} F A B$, fast-atom bombardment.

${ }^{b}(\mathrm{M}+\mathrm{H})^{+}$measured at the peak centroid.

or tyrosine, requires a $\mathrm{pH}$ above 10.5 to remove the $O$-acetyl group [16].

An example of the effect that acetyl lysine has on the CID spectrum of a chymotryptic peptide from an acetylated protein is shown in Figure 4a. First, its presence is revealed by the abundant ion at $m / z 126$ (labeled KAc), which is formed by the loss of ammonia from the immonitum ion of acetylated lysine, $m / z 143$, and is thus the acetyl analog of the cyclic immonium ion of $m / z 84$, characteristic of lysine $(\mathrm{m} / z$ is still formed by the loss of ketene from $m / z$ 126). There is also an ion (-KAc) corresponding to the loss of $114 \mathrm{u}$ (the entire acetylated side chain) from the $(\mathrm{M}+\mathrm{H})^{+}$ ion. Second, a mass difference of $170 \mathrm{u}$ between the $y_{6}$ ion $(m / z 638)$ and the $(\mathrm{M}+\mathrm{H})^{+}$ion $(m / z$ 808.6) also requires that the $N$-terminal amino acid be acetyllysine

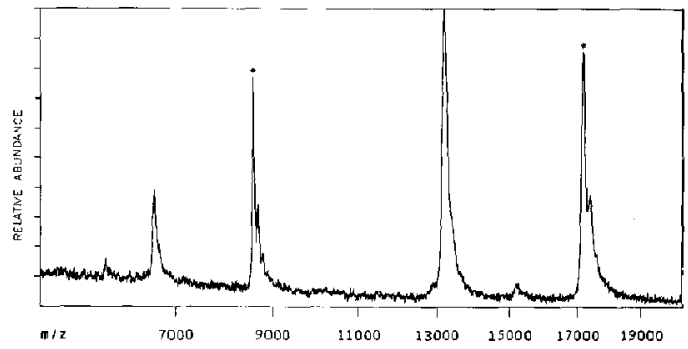

Figure 1. MALD spectrum of peracetylated cytochrome $c$. The peaks indicated by an asterisk are the $(\mathbf{M}+2 \mathrm{H})^{2+}$ and $(\mathrm{M}+\mathbf{H})^{+}$ ions, respectively, of the internal standard, sperm whale apomyoglobin $\left(\mathrm{M}_{\mathrm{r}}=17,199.9\right)$. and not glutamine. The fragment ion nomenclature used herein has been outlined elsewhere $[1,2]$.

The spectrum of the higher molecular weight component, $(\mathrm{M}+\mathrm{H})^{+}=m / z 850.5$ (Figure $4 \mathrm{~b}$ ), from the same sequence $(27-33)$ is similar, except that all of the peaks that are due to fragments containing the amino acid in position 28 are shifted by $42 \mathrm{u}$, which confirms that this threonine is acetylated. Of note, in this spectrum the $w_{6 a}$ ion is very abundant and the $w_{6 b}$ ion is absent, whereas in Figure $4 \mathrm{a}$ both are present but less abundant. This indicates that in the formation of $w_{n}$ ions, a $\mathrm{CH}_{3} \mathrm{COO}^{\circ}$ radical is lost much more readily than an $\mathrm{HO}^{\circ}$ radical.

The CID spectrum of the chymotryptic peptide (68-74) of $(\mathrm{M}+\mathrm{H})^{+}=m / z$ 975.6 is shown in Figure $5 \mathrm{a}$. This spectrum consists mainly of $\mathrm{b}_{n}$ - and $\mathrm{y}_{n}$-series ions and is characteristic of peptides that do not contain a basic amino acid. Although the $\mathrm{b}_{2}$ ion at $m / z$ 243 could be either $X-E$ or $N-Q$ (the possibility of $K$ is eliminated, because it would be acetylated), the presence of abundant immonium ions at $\mathrm{m} / \mathrm{z} 86$ and 102 indicates that it is probably $\mathrm{X}-\mathrm{E}$, although the order cannot be established because of the absence of a $y_{6}$ ion. Because $b_{n}$ and $y_{n}$-series ions are not precursors for side-chain cleavages, these spectra do not therefore exhibit either $\mathrm{d}_{n}$ or $\mathrm{w}_{n}$ ions and as a result cannot differentiate leucine from isoleucine; however, the spectrum clearly demonstrates that the two amino acids in positions 72 and 73 are both lysine rather than glutamine. An overlapping tryptic peptide, $(\mathrm{M}+\mathrm{H})^{+}=m / z 1495.8$ (Figure $5 \mathrm{~b}$ ), obtained from the 
Table 2. Chymotryptic digest of acetylated cytochrome $c$

\begin{tabular}{|c|c|c|c|}
\hline Position & $(\mathrm{M}+\mathrm{H})^{+}$measured $(\mathrm{FAB})^{\mathrm{a}}$ & Sequence & $\begin{array}{l}\text { HPLC }^{\mathrm{b}} \\
\text { Fraction }\end{array}$ \\
\hline $1-10$ & 1288.9 & GDVEKGKKIF & 13 \\
\hline $11-26$ & $2496.1^{\mathrm{c}}$ & (F)VOKC ...GGKH & 15 \\
\hline $27-33$ & 808.7 & (H)KTGPNLH & 2 \\
\hline $27-33$ & 850.6 & (H)KIGPNLH ${ }^{e}$ & 3 \\
\hline $27-36$ & 1125.4 & (H)KTGPNLHGLF & 14 \\
\hline $27-36$ & 1167.4 & $(H) K T G P N L H G L F{ }^{e}$ & 15 \\
\hline $37-48$ & 1324.7 & (F)GRKT ...GFTY & 7 \\
\hline $39-48$ & 1111.6 & (R)KTGQ...GFTY & 7 \\
\hline $49-59$ & 1331.7 & (Y)TDAN ... GITW & 10 \\
\hline $60-67$ & 1084.5 & (W)KEETLMEY & 9 \\
\hline $60-68$ & 1197.5 & (W)KEETLMEYL & 16 \\
\hline $66-67$ & 312.4 & (M)EY & 8 \\
\hline $68-74$ & 975.6 & (Y)LENPKKY & 5 \\
\hline $75-80$ & 688.4 & (Y)IPGTKM & 4 \\
\hline $81-82$ & 279.2 & $(\mathrm{M}) / \mathrm{F}$ & 7 \\
\hline $81-97$ & 2121.2 & (M)IFAG . . LIAY & 15 \\
\hline $75-82$ & 948.8 & (Y)IPGTKMIF & 16 \\
\hline $83-91$ & 1156.7 & (F)AGIKKKTER & 3 \\
\hline $83-97$ & 1861.0 & (F)AGIK ... LIAY & 11 \\
\hline $83-98$ & 1973.8 & (FIAGIK ... IAYL & 16 \\
\hline $95-97$ & 479.3 & (L)IAY & 10 \\
\hline $98-104$ & 887.7 & (Y)LKKATNE & 1 \\
\hline
\end{tabular}

${ }^{a} F A B$, Fast-atom bombardment.

'HPLC, high-performance liquid chromatography.

${ }^{c}(\mathrm{M}+\mathrm{H})^{+}$measured at the centroid.

"Contains heme.

I denotes $O$-acetylthreonine.

native protein underscores the complementarity of the CID mass spectra of the products of these two digests. This spectrum is dominated by $C$-terminal fragment ions owing to the presence of lysine at the $C$-terminus. It reveals both the order L-E (from the $y_{3}-y_{5}$ series) and establishes that position 68 is leucine rather than isoleucine on the basis of the $\mathrm{w}_{5}$ ion.

The complete acetylation of the 19 lysines and the $N$-terminal amino group of sperm whale apomyoglobin $\left(M_{r}=17199.9\right)$ is more difficult. After treatment of the acetylated protein with ammonium bicarbonate,

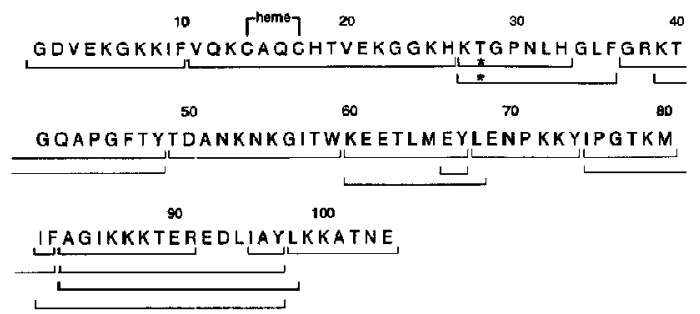

Figure 2. Amino acid sequence of horse heart cytochrome $c$. The peptides observed by FABMS on digestion of the acetylated protein with chymotrypsin are underlined by brackets; asterisks indicate that the peptide was found both with free and acetylated threonine (see Table 2 and text).

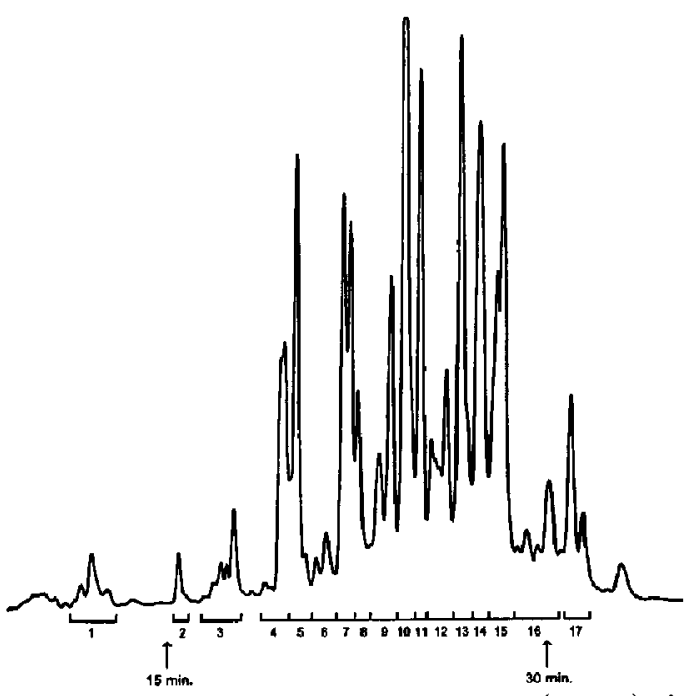

Figure 3. Separation by reversed-phase HPLC (214 $\mathrm{nm})$ of a 28-h chymotryptic digest of peracetylated cytochuome $c$. The solvent gradient varied and was kept shallow in the middle of the chromatogram. $0-15 \mathrm{~min}: 10 \%-35 \%$ acetonitrile in water (containing 0.05\% trifluoroacetic acid); $15-30 \mathrm{~min}: 35 \%-40 \%$; 30-35 min: 40\%-60\%. Seventeen fractions were collected as indicated. Fraction 17 is the heme, $(\mathrm{M}+\mathrm{H})^{+}=m / z$ 617.7. 

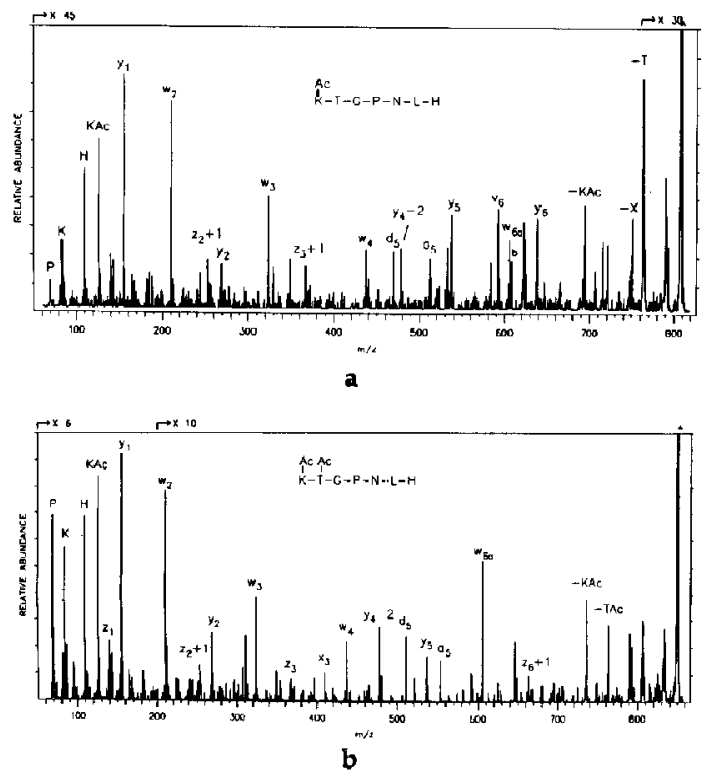

Figure 4. CID mass spectra of the chymotryptic peptides corresponding to the sequence 27-33 of cytochrome $c$ and representing (a) the monoacetylated peptide, precursor ion of $\mathrm{m} / z$ 808.7, and (b) the diacetylated peptide, precursor ion of $\mathrm{m} / \mathrm{z}$ 850.6. KAc refers to the cyclic immonium ion of acetylated lysine; -KAc indicates the loss of the acetyllysine side chain.

the product was analyzed by MALD (Figure 6). The broad peak (compared with the internal standard) indicates considerable inhomogeneity. The apex of the $(\mathrm{M}+\mathrm{H})^{+}$peak falls at $m / z \quad 17,531.4$, whereas the centroid of the top $25 \%$ of the peak is found at $\mathrm{m} / \mathrm{z}$
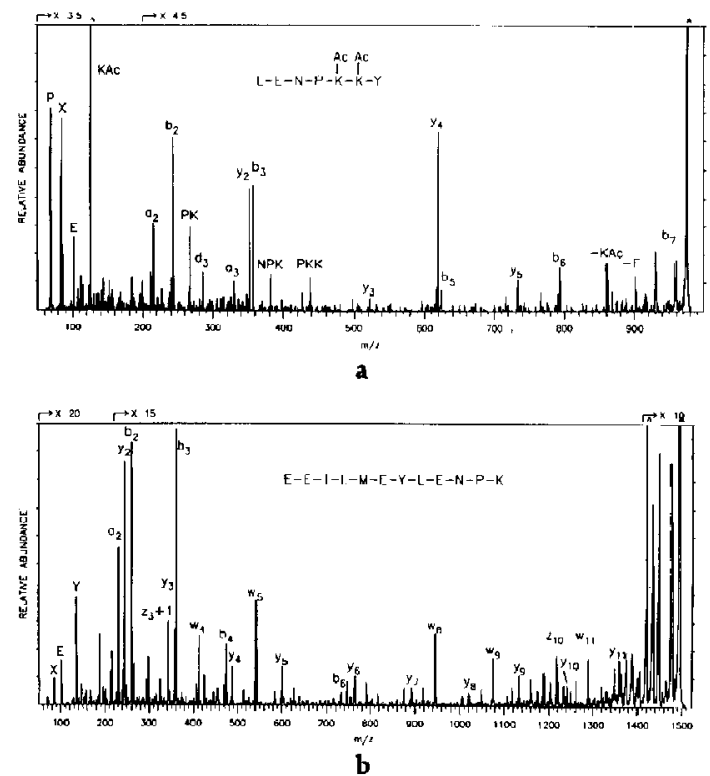

Figure 5. CID mass spectra of (a) the chymotryptic peptide 68-74 from acetylated cytochrome $c$, and (b) the tryptic peptide 61-72 from the native protein. $K A c$ and $-K A c$ as in Figure 4.

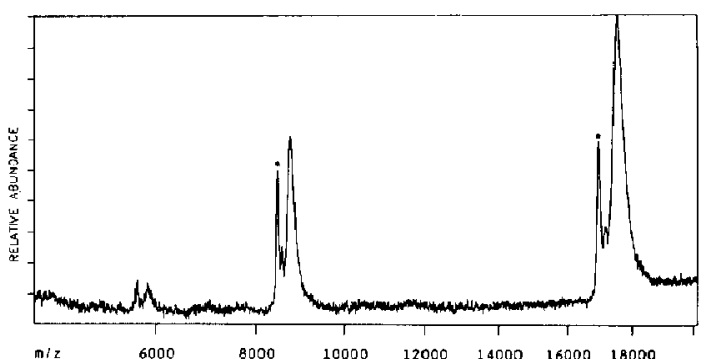

Figure 6. MALD spectrum of acetylated sperm whale myoglobin. The peaks indicated by an asterisk are the $(\mathrm{M}+2 \mathrm{H})^{2+}$ and $(\mathrm{M}+\mathrm{H})^{+}$ions, respectively, of the internal standard, horse heart apomyoglobin $\left(\mathrm{M}_{\mathrm{r}}=16,951.5\right)[15]$.

$17,538.3$ but at that point has a width of $200 \mathrm{u}$. These data suggest that although not all the lysines had been acetylated, a broad distribution of peracetylated species exists. Results from several of these experiments indicated that the average extent of acetylation was between $40 \%$ and $60 \%$. The partial underacetylation of the lysines is indicated in Figure 7, which details the results of a chymotryptic digest of acetylated sperm whale apomyoglobin. Although the mass-to-charge ratio values of the $(\mathrm{M}+\mathrm{H})^{+}$ions do not as such differentiate between $N$-acetylated lysine and any $O$ acetylated amino acids, the CID spectra of these peptides clearly indicate that in this case, only the lysines have been derivatized.

The degree of acetylation within a particular lysine-containing chymotryptic peptide varies from $0 \%$

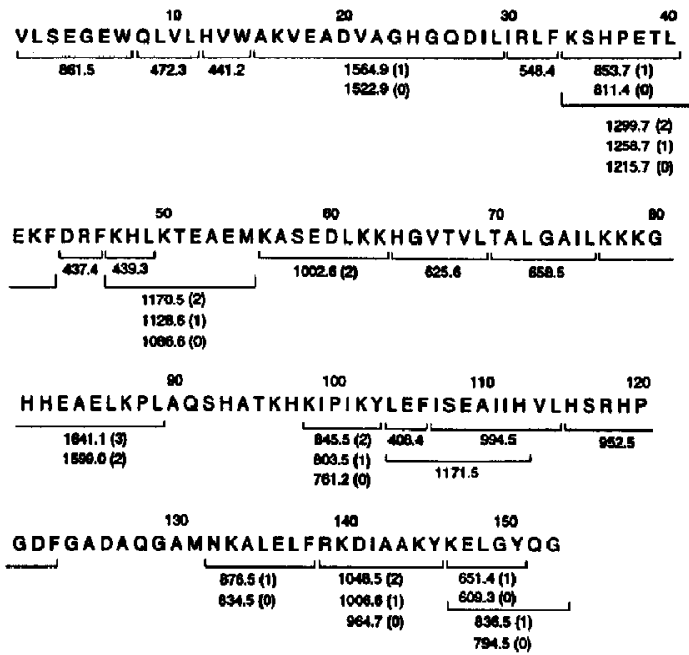

Figure 7. Amino acid sequence of sperm whale myoglobin. The peptides observed by FABMS on digestion of the acetylated protein with chymotrypsin are underlined by brackets. The numbers below the brackets correspond to the mass-to-charge ratio values observed for the $(\mathrm{M}+\mathrm{H})^{+}$ion. Values in parentheses indicate the number of acetyl groups incorporated. For clarity of presentation, additional peptides detected but that do not add further information are not shown. 
to $100 \%$ and can be random or specific. For example, reaction of the lysines at positions 140 and 145 gives rise to all four possible combinations for the sequence 139-146 (unreacted, two monoacetylated, and one diacetylated analog), $(\mathrm{M}+\mathrm{H})^{+}=m / z$ 964.7, 1006.6, and 1048.7, respectively. Because all of them have an $N$-terminal arginine, their CID spectra consist mainly of $\mathrm{a}_{n}$ and $\mathrm{d}_{n}$ ions. Figure 8a shows the CID spectra of the underivatized peptide, $(\mathrm{M}+\mathbf{H})^{+}=m / z 964.4$, and although there is a complete series of $\mathrm{a}_{n}$ and $\mathrm{d}_{n}$ ions, the amino acids in position 140 and 145 can be either $K$ or Q. Because these two amino acids have the same residue (128 $\mathrm{u}$ ) and side-chain (58 $\mathrm{u}$ ) mass, they give an identical set of $\mathrm{a}_{n}$ and $\mathrm{d}_{n}$ ions. The CID spectrum of the diacetyl derivative $(\mathrm{M}+\mathrm{H})^{+}=m / z 1048.6$ shown in Figure 8c, however, allows unambiguous assignment of positions 140 and 145 as lysine. After acetylation, the mass-to-charge ratio values of the $a_{2}-a_{6}$ and $\mathrm{d}_{3}, \mathrm{~d}_{4}$ ions have been shifted by $+42 \mathrm{u}$ and $\mathrm{a}_{7}$ by +84 $u$, indicating that amino acids 140 and 145 must have
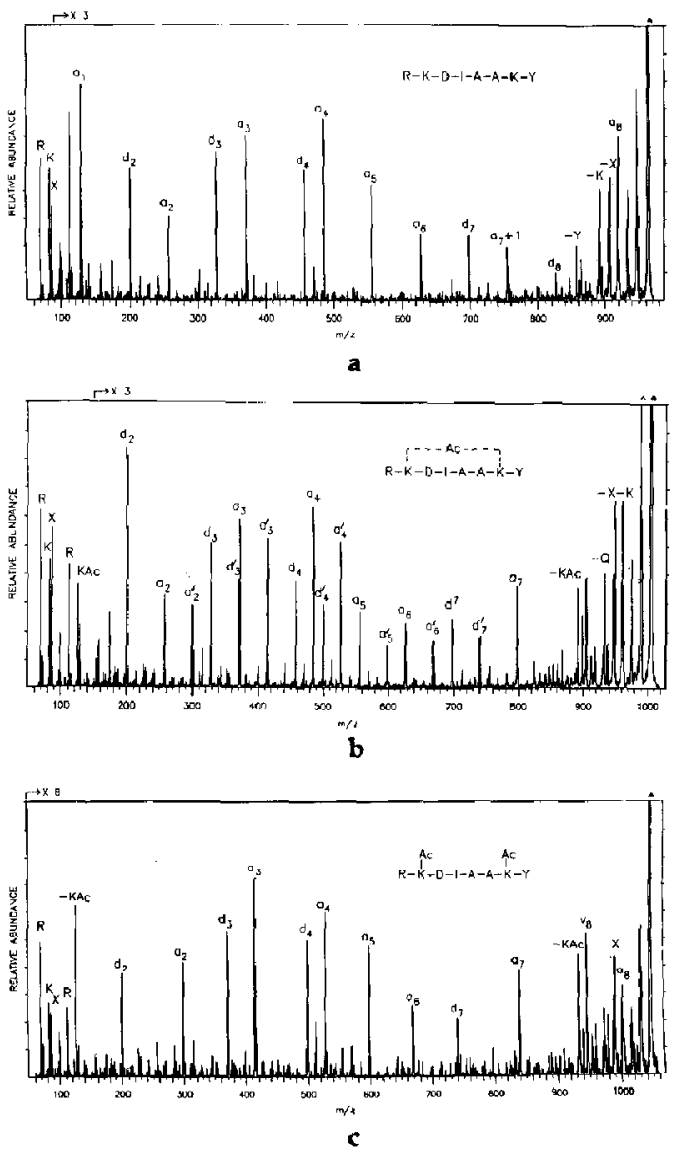

Figure 8. CID mass spectra of the peptides corresponding to various degrees of acetylation of the region 139-146 of myoglobin: (a) unacetylated, (b) monoacetylated, and (c) diacetylated. Fragments labeled $\mathrm{a}_{n}^{\prime}$ and $\mathrm{d}_{n}^{\prime}$ in $\mathbf{b}$ refer to those due to the isomer acetylated at Lys-140. been lysine and not glutamine, information that could not have been deduced from Figure 8a alone.

Figure $8 \mathrm{~b}$ is an interesting case. It represents the CID spectrum of a mixture of isomeric monoacetylated peptides $(\mathrm{M}+\mathrm{H})^{+}=m / z \quad 1006.6$ from the sequence 139-146, where the modification at position 145 is slightly more abundant. This conclusion can be easily reached from the fact that the ions $a_{2}-d_{7}$ appear as doublets, spaced $42 \mathfrak{u}$ apart, because these fragments retain only one lysine, including its side chain. On the other hand, the $d_{2}$ and $a_{7}$ ions are singlets, as are all ions of mass lower than $d_{2}$ and higher than $a_{7}$ because they contain either none or both of the lysines present in the peptide.

In contrast to the previous example, the CID spectrum of the chymotryptic peptide 34-43 (Figure 9) shows that of the two lysines at positions 34 and 42 , only the latter is acetylated. In this spectrum, which has an appearance typical of peptides with a basic amino acid at the $N$-terminus (mainly $\mathrm{a}_{n}$ and $\mathrm{d}_{n}$ ions), the mass-to-charge ratio values for all of the fragments are compatible with an unreacted $N$-terminal lysine. Furthermore, the mass difference between $a_{8}$ and $a_{9}+$ $1(171 \mathrm{u})$ indicates that the amino acid at position 42 is acetyllysine. If the lysine at position 34 had been acetylated instead, the spectrum would be dominated by the corresponding C-terminal fragment ions (none of which is observed), and all of the $N$-terminal ions originating from below position 42 would be shifted by $+42 \mathrm{u}$. Thus, in this case, both the appearance of the spectrum and the mass-to-charge ratio values of the fragment ions indicate that the amino acids 34 and 42 are Lys not Gln. This is also supported by the CID spectrum of the diacetylated peptide $(\mathrm{M}+\mathrm{H})^{+}=\mathrm{m} / \mathrm{z}$ 1299.9 (data not shown). Because the monoacetylated peptide $34-40$ has been detected in addition to the unreacted analog (see Figure 4), some of the peptide 34-43 acetylated at Lys-34 should also have been observed. It must have been chromatographically separated from the other isomer.

Table 4 summarizes the extent of acetylation derived from these and other analogous data, whereas Figure 7 represents the assignments of the observed chymotryptic peptides to the amino acid sequence of sperm whale myoglobin. Although peptides 90-97 and 124-131 were not observed, they were also not found

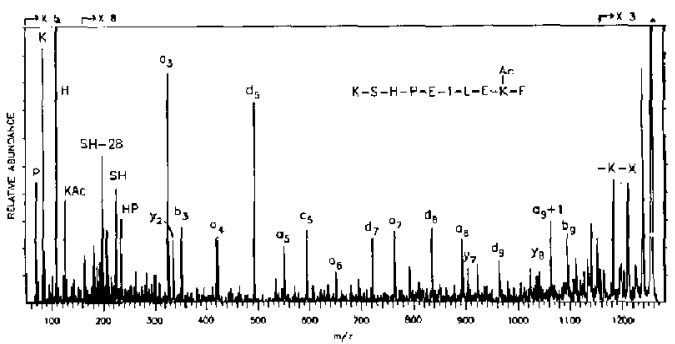

Figure 9. CID mass spectrum of the chymotryptic peptide $34-43$ from acetylated myoglobin $\left[(\mathrm{M}+\mathrm{H})^{+}=m / z\right.$ 1258.7] 
Table 3. Chymotryptic digest of sperm whale apomyoglobin

\begin{tabular}{ccl}
\hline Position & $\left(\mathrm{M}+\mathrm{H}^{+}\right.$measured (FAB) & \multicolumn{1}{c}{ Sequence } \\
\hline $1-7$ & 819.4 & VSLEGEW \\
$8-11$ & 472.4 & (W)QLVL \\
$12-14$ & 441.3 & (L)HVW \\
$15-29$ & 1523.1 & (W)AKVE . . QDIL \\
$30-33$ & 548.4 & (L)IRLF \\
$34-40$ & 811.4 & (F)KSHPETL \\
$34-46$ & 1633.9 & (F)KSHP ... FDRF \\
$44-50$ & 943.8 & (F)DRFKHLK \\
$48-55$ & 1086.6 & (K)HLKTEAEM \\
$56-69$ & 1525.1 & (M)KASE ... VTVL \\
$64-69$ & 625.5 & (K)HGVTVL \\
$70-76$ & 658.6 & (L)TALGAIL \\
$77-89$ & 1515.2 & (L)KKKG ... LKPL \\
$98-103$ & 761.5 & (H)KIPIKY \\
$98-104$ & 874.7 & (H)KIPIKYL \\
$104-106$ & 408.4 & (Y)LEF \\
$107-113$ & 782.4 & (F)ISEAIIH \\
$107-115$ & 994.8 & (F)ISEAIHHL \\
$116-123$ & 952.6 & (L)HSRHPGDF \\
$132-137$ & 834.5 & (M)NKALELF \\
$134-140$ & 876.4 & (K)ALELFRK \\
$139-146$ & 964.7 & (R)KDIAAKY \\
$147-151$ & 609.3 & (Y)KELGY \\
$147-153$ & 794.5 & (Y)KELGYOG \\
\hline
\end{tabular}

aAB, fast-atom bombardment.

in the digest of the native protein. In contrast to cytochrome c, sperm whale apomyoglobin can be fully digested in 3-6h; thus, the unacetylated digest of this protein reveals little cleavage at tryptic sites. The extent of sequence coverage by the chymotrypic digests of native and acetylated apomyoglobin is therefore similar (compare Table 3 with the data in Figure 7); how- ever, the results from the digest of the acetylated protein clearly define all of the lysines present and differentiate them from glutamine by a single experiment.

Although the molecular weight information provided by MALD indicated an average of only $40 \%-60 \%$ acetylation, the FABMS and CID data

Table 4. Distribution of the sites of acetylation in some chymotryptic myoglobin peptides containing more than one lysine

\begin{tabular}{|c|c|c|c|}
\hline Position & Sequence & $\begin{array}{l}\text { Mass-to-charge ratio } \\
\text { observed }(\mathrm{FAB})^{\mathrm{a}}\end{array}$ & Site of acetylation \\
\hline \multirow[t]{3}{*}{$34-43$} & KSHPETLEKF & $(0)^{b} 1215.7(1)^{b}$ & \\
\hline & & (1) $1258.7(1)$ & Completely K42 \\
\hline & & (2) $1299.9(1)$ & \\
\hline \multirow[t]{3}{*}{$47-55$} & KHLLKTEAEM & (0) $1086.6(1)$ & \\
\hline & & (1) $1128.6(4)$ & Predominately K47 \\
\hline & & (2) $1170.6(2)$ & \\
\hline \multirow[t]{3}{*}{$98-103$} & $\underline{\text { KIPIKYY }}$ & (0) $761.2(2)$ & \\
\hline & & (1) $803.5(1)$ & 3:1 K98:K102 \\
\hline & & (2) $845.6(3)$ & \\
\hline \multirow[t]{3}{*}{$139-146$} & RKEIAAKKY & (o) $964.7(1)$ & \\
\hline & & (1) $1006.6(3)$ & Aimost equimolar K140:K145 \\
\hline & & (2) $1048.7(1)$ & \\
\hline
\end{tabular}

a FAB, fast-atom bombardment

${ }^{b}$ Number of lysines acetylated.

'Relative abundance. 

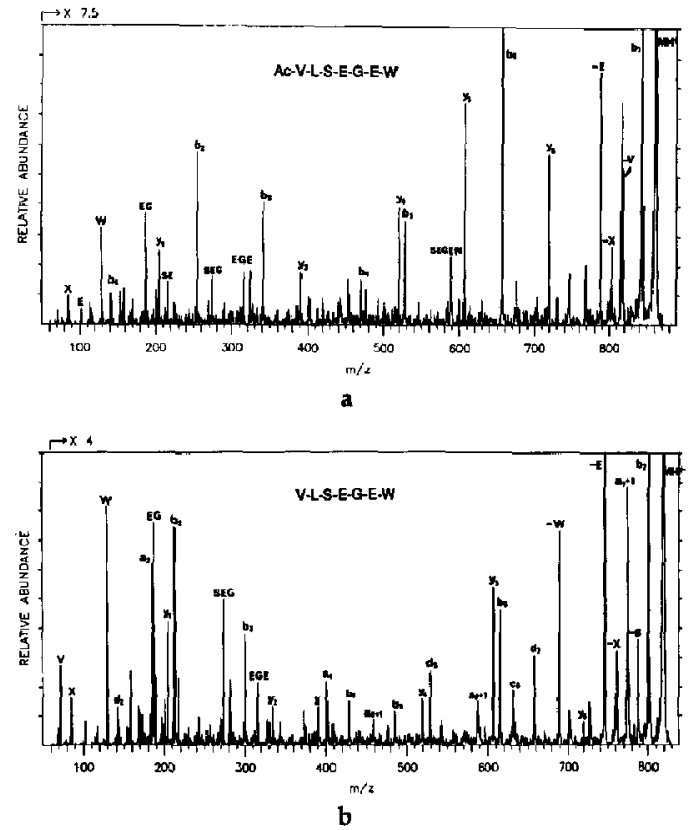

Figure 10. CID mass spectrum of the $N$-terminal chymotryptic peptide $(1-7)$ from (a) acetylated and (b) native myoglobin.

showed that in all cases, fully acetylated lysinecontaining peptides were detected. The reason for the difficulty in achieving complete acetylation is unclear but is in agreement with earlier observations that between $60 \%$ and $90 \%$ acetylation can be considered typical [16]. The problem of incomplete acetylation is . likely to become more severe with much larger proteins. Because we have found that the previous acety lation protocol works well with smaller proteins, such as insulin and ubiquitin, an alternative strategy may be to first cleave the native protein into large $\left(\mathrm{M}_{\mathrm{r}}<\right.$ $10,000)$ polypeptides using $\mathrm{CNBr}$. These fragments should be easily acetylated and could then be digested with an appropriate enzyme, such as chymolrypsin or Endo Glu-C. We have found that the C-terminal $\mathrm{CNBr}$ fragment (132-153) of sperm whale apomyoglobin, a region that was difficult to acetylate in the intact protein, readily adds five acetyl groups, indicating that all four lysines and the $N$-terminus have been acetylated.

Finally, the $\mathrm{N}$-terminal peptide of the original protein can be easily identified (unless it is already blocked as in cytochrome $c$ ) in the digest of an acetylated product. The peptide incorporating the original $N$ terminal residue will be the only one with an acetylated $N$-terminus. Figure 10a represents the CID spectrum of one of the chymotryptic peptides $\left[(\mathrm{M}+\mathrm{H})^{-1}=\right.$ $m / z$ 861.5] from acetylated sperm whale myoglobin. The abundant $b_{n}$ and $y_{n}$ ion series establish the sequence as BXSEGEW, where $B$ is an amino acid of residue mass 141 . This corresponds to $\mathrm{N}$-acetyl valine. The assignment is further confirmed by the small but significant peak at $m / z 142$, which could be the $\mathrm{b}_{1}$ ion, a fragmentation that we have only observed in $N$ acetylated peptides [17]. This peptide must therefore represent the original $N$-terminus. Its unacetylated analog (Figure 10b) is observed in the chymotryptic digest of the native myoglobin. Because this peptide retains the basic $N$-terminal amino group, the corresponding CID spectrum is dominated by $N$-terminal ions, and the clearly observable $\mathrm{d}_{2}$ ion defines the amino acid in position 2 as leucine rather than isoleucine.

\section{Conclusions}

Although it is difficult to completely and exclusively acetylate the $\varepsilon$-amino groups in proteins (except smaller ones) under the conditions described, a proteolytic digest of the product provides very useful information complementary to that obtained from digests of the native protein. Most important, the CID spectra of the $(\mathrm{M}+\mathrm{H})^{+}$ions of the peptides from the acetylated protein permit direct differentiation of lysine from glutamine and eliminate the separate acetylation of various fractions containing peptides in which this ambiguity would otherwise remain. We have shown previously that acetylation of lysines, which occurs in the interior of the peptide sequence (such as are produced by chymotryptic and Endo Glu-C digests), can simplify the CID spectra by reducing the number of the fragmentation dirccting basic sites [18]. Furthermore, conversion of lysine to a nonbasic amino acid simplifies chymotryptic digests that have to be carried out over a relatively long time, which often leads to additional trypsinlike cleavage. Finally, the original $N$-terminal peptide will be acetylated at the first amino acid and thus will be readily recognized. The results presented here suggest that at least one digest of acetylated protein should be incorporated into the strategies for MS/MS sequencing of proteins.

\section{Acknowledgments}

This work was supported by NIH research grants from the National Institute of General Medical Sciences (GM05472) and the Center for Research Resources (RROMB17).

\section{References}

1. McCloskey, J. A., Ed. Methods in Enzymology, Vol. 193; Academic: San Diego, 1990; Chapters 18-28 and Appendices 5 and 6.

2. Biemann, K. Biomed. Environ. Mass Spectrom. 1988, 16, 99-111.

3. Hunt, D. F.; Shabanowitz, J.; Yates, J. R.; Griffin, P. R.; Zhu, N. Z. In Mass Spectrometry of Biological Materials; McEwen, C.N.; Larsen, B. S., Eds.; Matcel Dekker: New York, 1990; p. 169.

4. Johnson, R. S.; Martin, S. A.; Biemann, K. Int. J. Mass Spectrom. Ion Proc. 1988, 86, 137-154.

5. Hopper, S.; Johnson, R. S.; Vath, J. E; Biemann, K. J. Biol. Chem, 1989, 264, 20438-20447.

6. Vath, J. E.; Biemann, K. Int. J. Mass Spectrom. Ion Proc. 1990, 100, 287-299. 
7. Watson, J. T.; Wagner, D. S.; Chang, Y.-S.; Strahler, J. R.; Hanash, S. M.; Gage, D. A. Int. J. Mass, Spectrom. Ion Proc. 1991, 111, 191-209.

8. Johnson, R. S.; Martin, S. A.; Biemann, K.; Stults, J. T.; Watson, J. T. Anal. Chem. 1987, 59, 2621-2625.

9. Kassel, D. B.; Biemann, K. Anal. Chem. 1990, 62, 1691-1695.

10. Karas, M.; Hillenkamp, F. Anal. Chem. 1988, 60, 2299-2301.

11. Meng, C. K.; Mann, M.; Fenn, J. B. Z. Phys. D 1988, 10, 361-368.

12. Allen, G. Sequencing of Proteins and Peptides, 2ud ed.; Elsevier. Amsterdam, 1989; p. 33.
13. Sato, K.; Asada, T.; Ishihara, M.; Kunihiro, F.; Kammei, Y.; Kubota, E.; Costello, C. E.; Martin, S. A.; Scoble, H. A.; Biemann, K. Anal. Chem. 1987, 59, 1652-1659.

14. Margoliash, E.; Smith, E. L.; Krell, G.; Tuppy, H. Nature 1961, $192,1125$.

15. Zaia, J.; Annan, R. S.; Biemann, K. Rapid Commun. Mass Spectrom. 1992, 6, 32-36.

16. Riordan, J. F.; Vallee, B. L. Methods Enzymol. 1972, 25B, 494

17. Papayannopoulos, 1. A.; Gan, Z.-R.; Wells, W. W.; Biemann, K. Biochem. Biophlys, Res. Commun. 1989, 159, 1448-1454.

18. Biemann, K. Methods Enzymol. 1990, 193, 455-479. 